\title{
LUT
}

Lappeenranta

University of Technology

\section{Steam dewatering of filter cakes in a vertical filter press}

\author{
Kinnarinen Teemu, Häkkinen Antti, Ekberg Bjarne
}

This is a Final draft

version of a publication

published by Taylor \& Francis

in Drying Technology

DOI: $10.1080 / 07373937.2013 .780246$

Copyright of the original publication: () Taylor \& Francis 2013

Please cite the publication as follows:

Kinnarinen, T., Häkkinen, A., Ekberg, B., Steam dewatering of filter cakes in a vertical filter press, Drying Technology, 2013, 31: 1160-1169. DOI: 10.1080/07373937.2013.780246 


\title{
Steam dewatering of filter cakes in a vertical filter press
}

\author{
Teemu Kinnarinen ${ }^{*}$, Antti Häkkinen ${ }^{1}$, Bjarne Ekberg $^{2}$ \\ ${ }^{1}$ LUT Chemistry, Lappeenranta University of Technology, \\ P.O. Box 20, FI-53851 Lappeenranta, Finland \\ ${ }^{2}$ Outotec (Filters) Oy, Urusvuorenkatu 5, FI-20360 Turku, Finland \\ *Corresponding author tel: +358 40562 1398, e-mail: teemu.kinnarinen@lut.fi
}

\begin{abstract}
Steam dewatering of filter cakes is recognized as a competitive alternative to conventional air drying and thermally assisted mechanical dewatering (TAMD). The main benefit of cake dewatering with high-pressure steam is that mechanical and thermal dewatering can be efficiently performed in a single process step. The target of this study was to determine the potential of a steam dewatering technique for two industrial mineral suspensions. The first mineral, kaolin, was very difficult to dewater using conventional mechanical dewatering techniques, whereas the second one, ground calcium carbonate (GCC), represented only moderate resistance to filtration. The secondary objective was to compare the filterability of the original kaolin slurry with the same slurry treated with a coagulant (aluminium sulphate, $\mathrm{Al}_{2}\left(\mathrm{SO}_{4}\right)_{3} \cdot 16 \mathrm{H}_{2} \mathrm{O}$ ). Four different kinds of experiments were performed; tests without any kind of cake dewatering, tests with air drying, tests with steam drying, and tests with both coagulation and steam drying. The obtained results show that steam dewatering is an efficient technique for achieving lower cake moisture contents. Also, the positive influence of coagulation on the filtration capacity was found to be considerable in the case of kaolin. An approximate energy balance was created for the steam drying process and the determined energy efficiencies were compared with those obtainable with an ideal thermal drier. The main conclusion from these comparisons is that steam drying can be effectively used instead of traditional thermal drying, if the large energy losses can be reduced by proper insulation and heat recovery systems.
\end{abstract}

Keywords: $\quad$ Steam dewatering, filter press, kaolin, ground calcium carbonate (GCC), energy balance

\section{Symbols and abbreviations}

$A$

$C$

$C_{L}$

$C_{S}$

$c_{F}$

$c_{K}$

$c_{L}$

CS

D

$h$ filtration area, i.e. area of filter cake

heat capacity

heat capacity of liquid

heat capacity of solid

specific heat capacity of filtrate $\left(4.19 \mathrm{~kJ} \mathrm{~kg}^{-1}{ }^{\circ} \mathrm{C}^{-1}\right)$

specific heat capacity of kaolin $\left(0.88 \mathrm{~kJ} \mathrm{~kg}^{-1}{ }^{\circ} \mathrm{C}^{-1}\right)$

specific heat capacity of liquid

specific heat capacity of solid

particle diameter

height of filter cake 


$\begin{array}{ll}h_{F} & \text { specific enthalpy of filtrate } \\ h_{S} & \text { specific enthalpy of steam } \\ \Delta h_{v} & \text { enthalpy of vaporization } \\ m_{D . S .} & \text { mass of dry solids in filter cake } \\ m_{F} & \text { mass of filtrate } \\ m_{F, \text { cake }} & \text { mass of filtrate in filter cake after steam drying } \\ m_{F W, c a k e} & \text { mass of filtrate in filter cake before steam drying } \\ m_{S} & \text { mass of steam } \\ m_{W C} & \text { mass of filtrate in filter cake } \\ p & \text { pressure } \\ P & \text { power } \\ Q_{h} & \text { heat of evaporation for water at } 1.013 \mathrm{bar}, 100^{\circ} \mathrm{C} .(2257 \mathrm{~kJ} / \mathrm{kg}) \\ S & \text { liquid volume per pore volume } \\ t & \text { separation time } \\ T & \text { temperature } \\ T_{f} & \text { final temperature } \\ T_{i} & \text { initial temperature } \\ \Delta T & \text { temperature difference } \\ \eta & \\ \rho & \text { energy efficiency } \\ \rho_{L} & \text { density } \\ \rho_{s} & \text { density of liquid } \\ \rho_{s l} & \text { density of solid } \\ \phi & \text { density of slurry } \\ D . S . & \text { quantity of heat } \\ G C C & \text { dry solids } \\ & \text { ground calcium carbonate }\end{array}$

\section{Introduction}

The conventional techniques for dewatering cakes in filter presses are 1) mechanical compression and 2) air dewatering. These methods are not always effective in producing cakes of low-enough moisture. Alternative techniques for more efficient cake dewatering have therefore been developed. The use of steam instead of air in the cake dewatering stage has been investigated thoroughly by, for instance, Peuker and Stahl [1-4] who have contributed a great deal of fundamental work on the topic. In the field of coal dewatering, steam pressure filtration has been studied by, among others, Gerl and Stahl [5], Bongers et al. [6] and Chen et al. [7]. Thermally assisted mechanical dewatering (TAMD) with heating elements installed in the filter chamber has been studied by Couturier et al. [8], Mahmoud et al. [9], and Chantoiseau and Arlabosse [10]. Additionally, Bott and Langeloh [11] have detailed commercial steam-assisted hyperbaric disc and drum filters. Although many experimental studies have shown the obvious advantages of steam as the drying agent, the utilization of steam dewatering in large industrial process filters is still negligible. Furthermore, surprisingly few experimental studies have been previously published on the topic, even though 
steam drying techniques in general have been utilized for selected applications since the middle of the $20^{\text {th }}$ century [12]. Superheated steam has been used for drying paper [13], timber [14], various biomaterials [15] and, perhaps most importantly, food products [16-18]. Steam dewatering can be an effective alternative for slurries with high proportions of fines, for instance different mineral pigments and fillers. The aim of this study was to evaluate the performance of the steam dewatering technique for two different mineral slurries (kaolin and GCC) and to consider the energy consumption of the process.

\section{Materials and methods}

\subsection{Properties of the kaolin slurry}

The solids concentration and the density of the kaolin slurry, obtained directly from an industrial process, were $53 \mathrm{wt} . \%$ and $1500 \mathrm{~kg} / \mathrm{m}^{3}$, respectively. The suspension was intensively mixed before the tests to ensure a high degree of homogeneity. A very typical characteristic of kaolin is that the fines content is relatively high. Due to the high proportion of fine particles, filtration of the slurry is difficult.

The size distribution of the particles, on a volumetric basis, was measured with a Beckman Coulter LS 13320 laser diffraction analyzer. As Fig. 1A shows, the average characteristics of 10 parallel runs were as follows: $D_{\text {mean }}=4.05 \mu \mathrm{m}, D_{\text {median }}=3.67 \mu \mathrm{m}, D_{10}=0.43 \mu \mathrm{m}, D_{50}=3.67 \mu \mathrm{m}$, and $D_{90}$ $=8.25 \mu \mathrm{m}$.

The liquid in the slurry was water $\left(\rho \approx 1000 \mathrm{~kg} / \mathrm{m}^{3}\right)$, the temperature of the slurry was approximately $25^{\circ} \mathrm{C}$ and the $\mathrm{pH}$ was 6.2 . Some of the tests were performed with a slurry after the addition of aluminium sulphate $\left(\mathrm{Al}_{2}\left(\mathrm{SO}_{4}\right)_{3} \cdot 16 \mathrm{H}_{2} \mathrm{O}\right)$ as a coagulant. A suitable coagulant dosage was found to be approximately $0.8 \mathrm{~g}\left(\mathrm{Al}_{2}\left(\mathrm{SO}_{4}\right)_{3} \cdot 16 \mathrm{H}_{2} \mathrm{O}\right) / \mathrm{kg}_{\text {solids. }}$.

\subsection{Properties of the GCC slurry}

The second type of solid investigated was GCC. The slurry was filtered at a solids concentration of 35 wt. $\%\left(\rho=1260 \mathrm{~kg} / \mathrm{m}^{3}\right)$ and the temperature of the slurry was approximately $22{ }^{\circ} \mathrm{C}$ during the experiments. Preparation of the slurry prior to filtration was similar that of the kaolin. The GCC was filtered as it was, i.e. coagulants were not used in order to improve the filtration rate. As Fig. 1B shows, the average characteristics of 10 parallel runs were as follows: $D_{\text {mean }}=5.41 \mu \mathrm{m}, D_{\text {median }}$ $=4.79 \mu \mathrm{m}, D_{10}=0.32 \mu \mathrm{m}, D_{50}=4.79 \mu \mathrm{m}$, and $D_{90}=11.88 \mu \mathrm{m}$. 


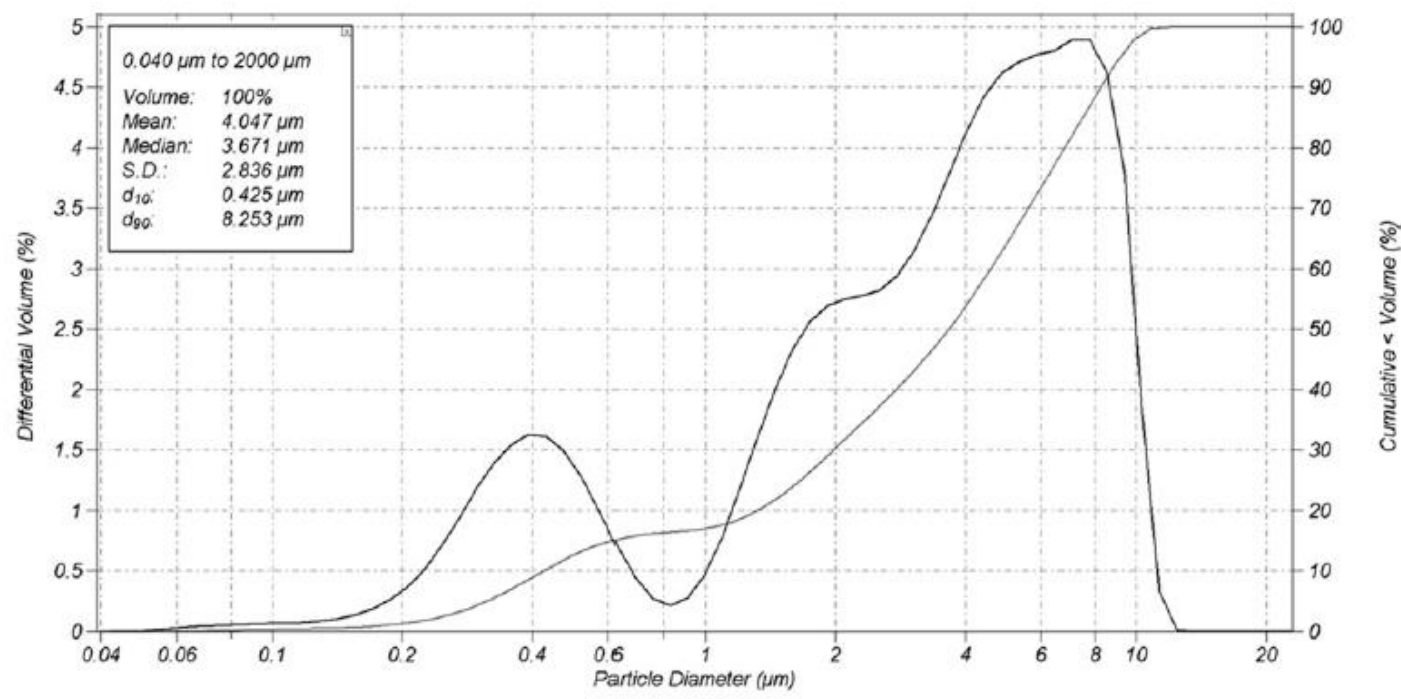

(A)

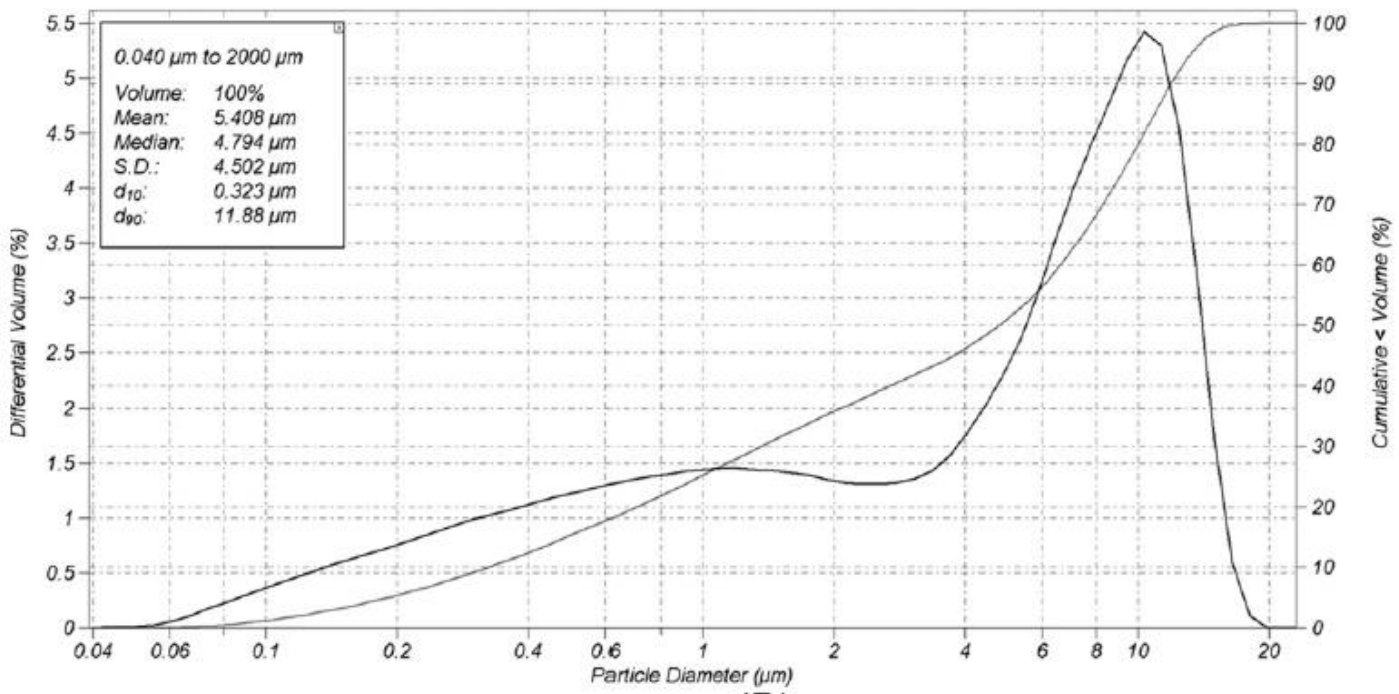

(B)

Fig. 1. A) Differential and cumulative particle size distributions of 10 parallel runs for the kaolin slurry. B) Differential and cumulative particle size distributions of 10 parallel runs for the GCC slurry.

\subsection{Filtration equipment}

A Larox PF 0.1 pressure filter (Fig. 2) was used in all filtration tests, with a filtration area of 0.1 $\mathrm{m}^{2}$ and a chamber height of $33 \mathrm{~mm}$. In order to avoid damage caused by high temperatures, the conventional elastomer compression diaphragm of the test filter was replaced with a diaphragm made of heat-resistant silicone. The filter cloths were also of a heat-resistant type, made of polyester. The filter cloths were successfully used without any cloth damage during the tests. The normal polypropene support grid under the cloth was replaced by a one made of stainless steel. 


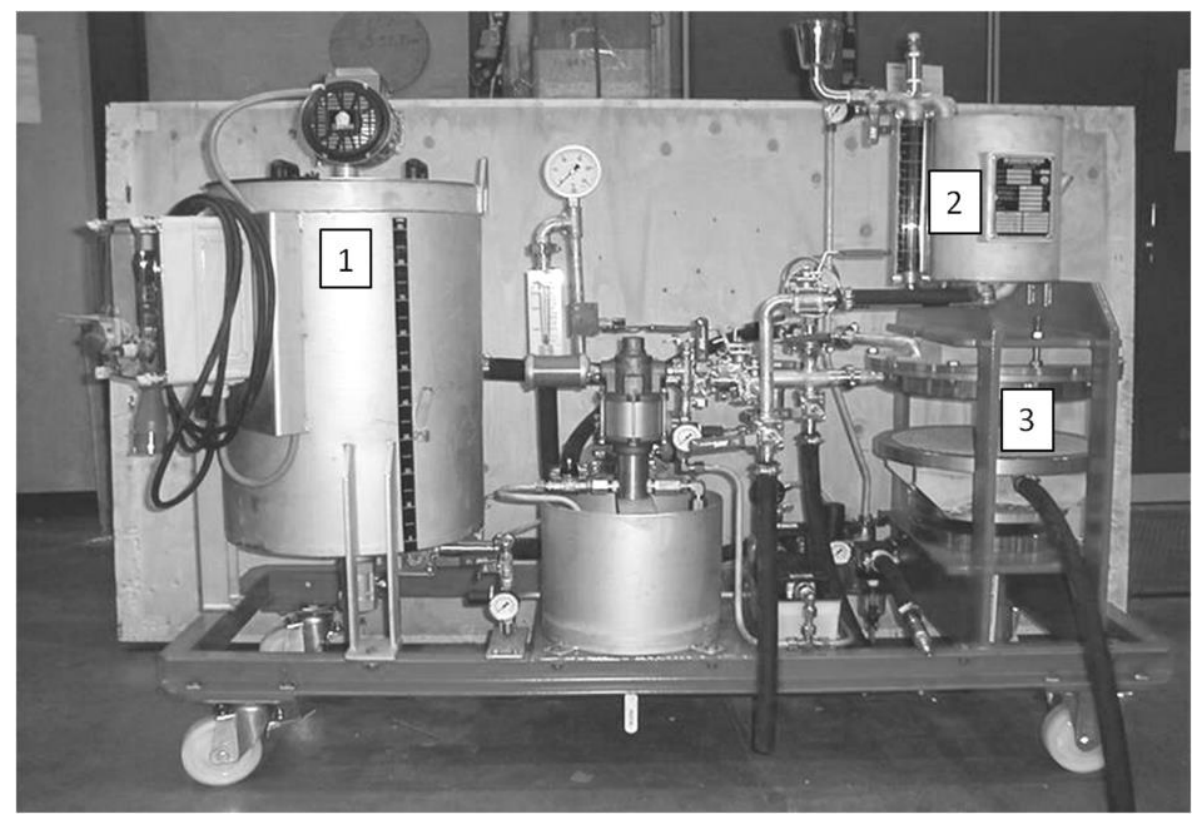

Fig. 2. Larox PF 0.1 pressure filter. 1) slurry tank, 2) wash water tank, 3) filter chamber. The pressing water tank is located between the slurry tank and the filter chamber.

The filter unit was equipped with automatic data collection software, which was used to record the compression pressure, cake temperature, filtrate temperature and filtrate mass once per second. There were two temperature sensors installed into the test unit for these experiments: one inside the filtration chamber, about $15 \mathrm{~mm}$ above the cloth and the second a few millimeters below the filter cloth.

One potentially important instrument that was missing from the test unit was a flowmeter for measuring the flow rate of steam. The steam consumption during the drying stage had therefore to be estimated, based on the amount of filtrate (i.e. condensed steam) accumulated during the steam drying stage. The saturated steam used for cake drying was generated by a Steam 500 movable steam generator $(\mathrm{P}=0.34 \mathrm{MW}$, capacity $=500 \mathrm{~kg} / \mathrm{h})$. The pressures of the steam used for drying were $3,6,8,9$ or 10 bar. The steam was fed into the filter chamber via the wash water inlet.

The filtration cycle consisted of the following stages: 1) Pumping / filtration (5 bar), 2) Pressing (8 or 16 bar), and 3) Drying with air (6 bar for kaolin, 5 bar for GCC) or steam (6-10 bar for kaolin, 3-9 bar for GCC). The tests were divided into four categories: tests without any kind of cake drying, tests with air drying, tests with steam drying and (for kaolin) tests with both coagulation and steam drying. First, two tests including only the filtration ( 5 bar) and pressing (16 and 8 bar) stages were performed without coagulant. The filtration times in the 16 bar and 8 bar tests were $25 \mathrm{~s}$ and $180 \mathrm{~s}$, respectively. The aim of these tests was to obtain reference values about the cake moisture contents prior to steam drying for evaluating the drying efficiency. After these two tests, four tests were carried out by applying conventional air drying at 6 bar. The drying stage was continued for 5 minutes in order to obtain the lowest possible cake moisture content that could be practically achieved by air drying at 6 bar. 


\subsection{Filtration and steam drying of kaolin}

The first series of steam drying tests consisted of 12 experiments (Table 1), which were carried out on non-coagulated slurries. Additionally, 10 experiments were carried out after coagulant addition, using a dose of $0.8 \mathrm{~g} \mathrm{Al}_{2}\left(\mathrm{SO}_{4}\right)_{3} \cdot 16 \mathrm{H}_{2} \mathrm{O} / \mathrm{kg}_{\text {solids. }}$. The temperatures of the saturated steam at 6,8 and 10 bar were 159,170 and $180{ }^{\circ} \mathrm{C}$, respectively. During the filtration stage, the feed pressure was held constant and the duration of the pumping stage was chosen to be either 'short' or 'long'.

'Short' pumping means that the feed pump was stopped about 10 seconds after the flow of filtrate started. This means that the total duration of the filtration stage was typically about 20-30 s, the constant pressure period being shorter. 'Long' pumping, on the other hand, was intended to be 180 $\mathrm{s}$ from the start of the filtrate flow. When the tests were performed without the coagulant addition, these pumping times could easily be reached. However, when coagulant was added into the slurry, it was noticed that about $100 \mathrm{~s}$ was the maximum pumping time that could be achieved. This was because of the apparent risk of blocking the feed pipe with the thickening slurry.

The pressing stage was performed using two different pressures (and the average of these, in Test 28 ) and the duration of the pressing was determined by the so-called X-point. This means that the pressing stage was stopped when a significant drop was observed in the feed line pressure, which actually happened when the compression diaphragm blocked the slurry feed port. Similarly, the duration of the steam drying stage was equal to the steam breakthrough time, which was easy to determine based on the lower temperature sensor as well as based on visual observations (steam flow from the filtrate outlet).

In addition to the experimental plan presented in Table 1, two tests (1-2) were carried out without any drying (only filtration and pressing). Air drying of filter cakes was performed in four experiments (3-6). Apart from the drying stage, Tests 1 and 6 were similar to Test 10, Tests 2 and 5 were similar to Test 9 , and Tests 3 and 4 corresponded to Tests 7 and 8 , respectively.

\subsection{Filtration and steam drying of GCC}

In addition to the tests with a difficult-to-filter kaolin slurry, a large series of experiments was carried out with GCC that was significantly coarser and also much easier to separate. The experimental plan for the experiments performed using GCC is presented in Table 2. Tests A1-A9 were performed with air drying, Tests S1-S10 with steam drying at 6 bar, Tests S11-S20 at 3 bar, and Tests S21-S30 at 9 bar.

\subsection{Progress of steam drying}

The steam drying stage was always continued until the steam started to flow from the filtrate pipe, i.e. until the breakthrough point mentioned earlier was reached. This point was also very clearly detected from the temperature data collected during the tests. An example of the experimental data collected is presented in Figure 3, showing the filtrate mass and filtrate temperature for one of the experiments. 


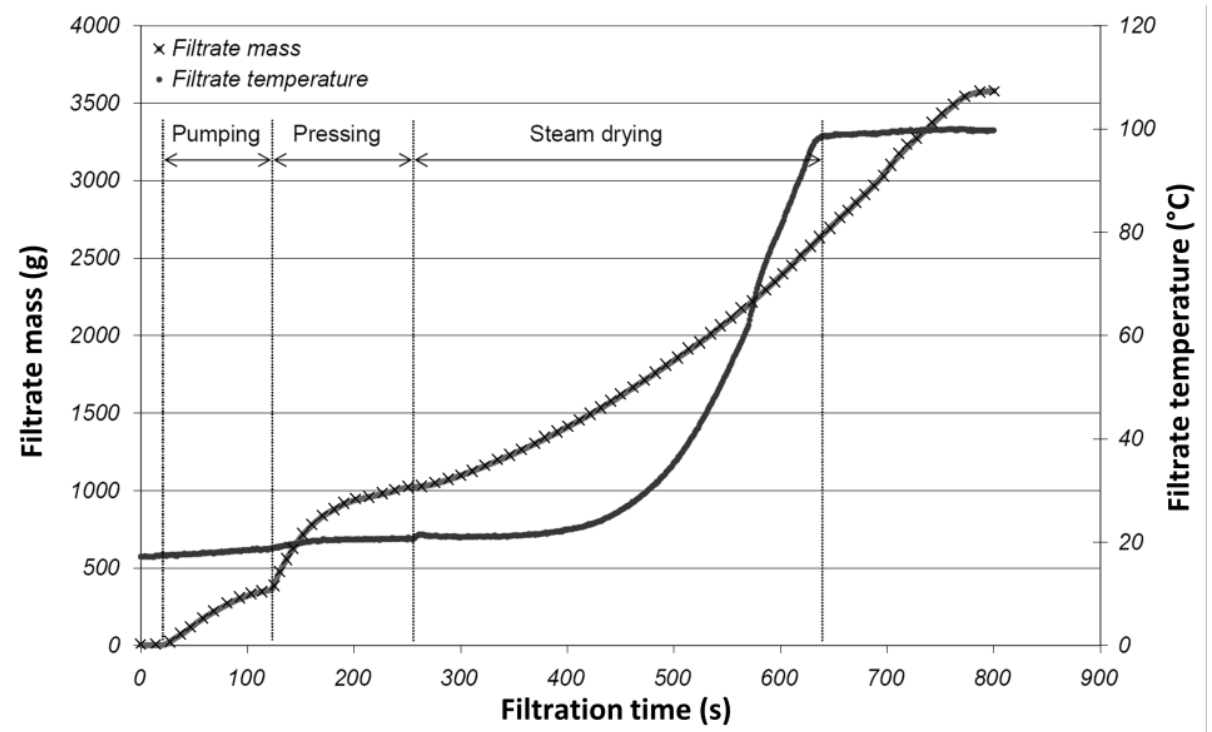

Fig. 3. An example of the data collected during one of the filtration tests.

The duration of the pumping stage in this particular example was about $100 \mathrm{~s}$ and it was followed by a relatively short cake pressing $(\approx 120 \mathrm{~s})$. The temperature of the filtrate was practically constant during the pumping and pressing and started to increase halfway during the steam drying stage as the cake and the filtrate heated up.

The breakthrough of steam through the cake is seen as a very sharp change in the temperature curve at about $640 \mathrm{~s}$. This is the point when the filtrate temperature reaches $99{ }^{\circ} \mathrm{C}$ and was considered to be the end point of steam drying in all tests. The duration of the steam drying stage varied widely, from 147 to 1796 seconds, depending on the other process conditions.

\subsection{Handling of filter cakes}

The cakes obtained from the experiments were analyzed for mass, thickness and moisture content. Determination of the moisture content was performed by drying the cake samples in a heating chamber at $105^{\circ} \mathrm{C}$, until a constant cake mass was obtained. Cake thickness was measured at five points, the average of which was then calculated.

\subsection{Equations}

The heat capacity, $C$, of a wet porous system, such as a filter cake, can be calculated as the sum of the heat capacity solid $\left(C_{S}\right)$ and the liquid $\left(C_{L}\right)$ :

$C=(1-\varepsilon) C_{S}+\varepsilon S C_{L}$

where $\varepsilon$ is the porosity and $S$ is the saturation, i.e. the ratio of liquid per pore volume.

The mass of steam $m_{s}$ needed to heat a filter cake from the initial temperature $T_{i}$ to the final temperature $T_{f}$ can be estimated using the following Equation: 
$m_{S}=\frac{\left[(1-\varepsilon) \rho_{s} c_{s}+\varepsilon \cdot S \cdot \rho_{L} c_{L}\right] h \cdot A\left(T_{f}(p)-T_{i}\right)}{\Delta h_{v}}$

where $\rho_{S}$ is the density of the solid, $c_{S}$ is the specific heat capacity of the solid, $c_{L}$ is the specific heat capacity of the liquid, $\rho_{L}$ is the density of the liquid, $h$ and $A$ are the height and area of the filter cake respectively and $\Delta h_{v}$ is the enthalpy of vaporization. More calculations concerning the energy consumption are presented in Section 4.

The density of solid used in Eq.(2) is calculated from Eq. (3):

$\rho_{s}=\frac{c_{w} \rho_{s l} \rho_{L}}{\rho_{L}-\rho_{s l}\left(1-c_{w}\right)}$

where $c_{w}$ is the dimensionless solid content of the slurry and $\rho_{s l}$ is the density of slurry. Density of kaolin and GCC were calculated to be $2460 \mathrm{~kg} / \mathrm{m}^{3}$ and $2500 \mathrm{~kg} / \mathrm{m}^{3}$, respectively.

In this study, the production capacity of a pressure filter is defined as the gross capacity, which means that the technical time required for cake discharge, cloth washing, filter opening and closing etc. is excluded.

Capacity $=\frac{m_{D . S}}{A t}$

where $m_{D . S}$ is the mass of dry solids in the filter cake, $A$ is the area of the filter and $t$ is the separation time including filtration, cake pressing and drying.

\section{Results and discussion}

\subsection{Cake properties and filtration capacities}

The cake moisture contents and the filtration capacities obtained from all tests are presented in Fig. 4. Although this figure does not show the exact experimental conditions for the individual tests, it can be seen that the lowest cake moisture contents and highest capacities are in fact found in the same tests. This is because the temperature of the saturated steam is also higher at higher pressures. Because the cakes were heated to a higher temperature, the removal of moisture was accelerated as the liquid viscosity was reduced. The steam breakthrough times and the corresponding cake thicknesses for kaolin and GCC are presented in Table 3. The test variables have been listed earlier in Tables 1-2. 


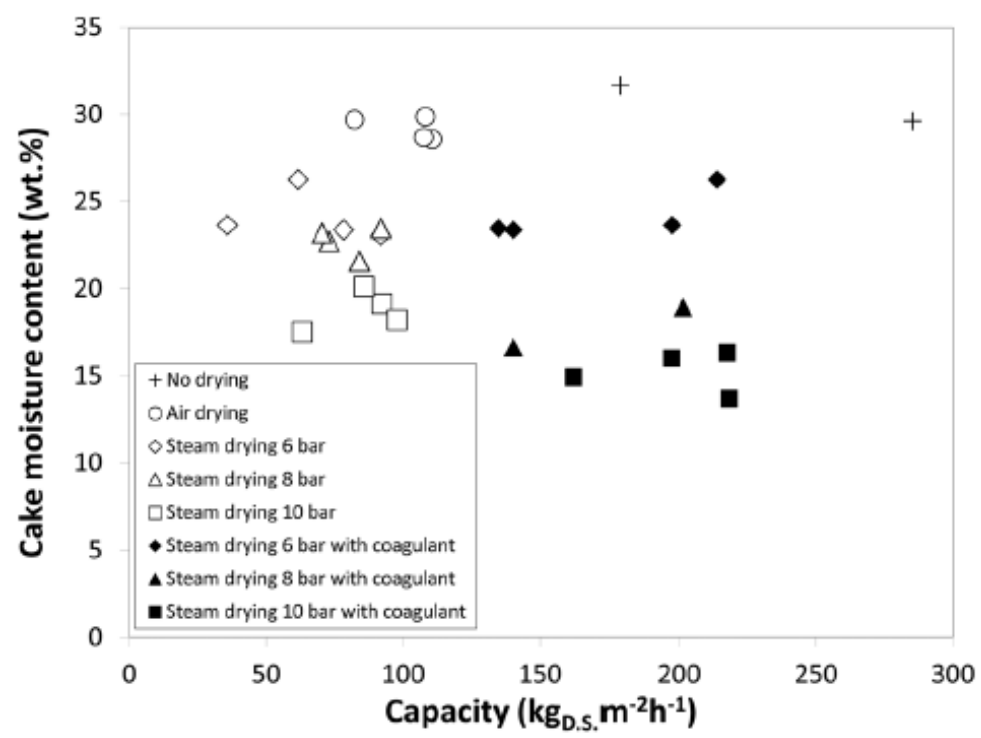

(A)

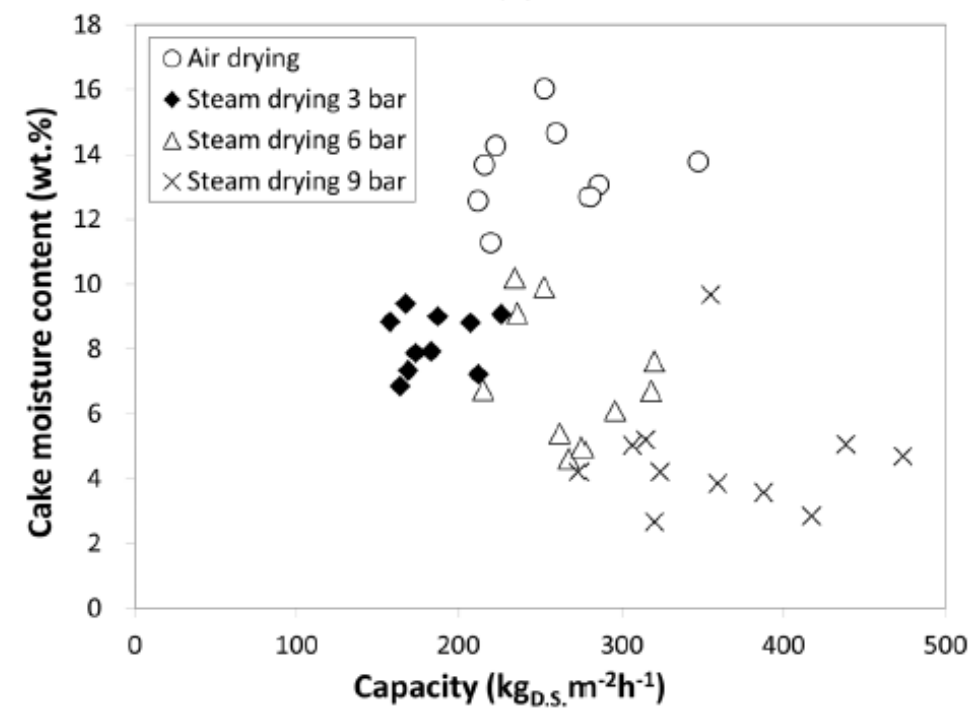

(B)

Fig. 4. Cake moisture contents vs. capacities for all tests. Dewatering of kaolin (A) and GCC (B).

In the kaolin experiments (Fig. 4A), the lowest obtained cake moisture content was 13.7 wt.\%. The highest moisture contents, approximately $30 \mathrm{wt} . \%$, are, as expected, obtained from the tests where the cakes were not dried at all. It is interesting to notice that the moistures of the cakes from the tests with air drying are only about 1-2 wt.\% lower. This means that the effectiveness of air drying was very poor in this case.

It is clearly apparent that the addition of coagulant improves filtration. This is likely to be due to the more open cake structure which results in faster filtration rates during the feeding, shorter pressing times and a lower resistance to the flow of steam through the cake. Highest capacities, in 
terms of $\mathrm{kg}_{\text {D.S. }} / \mathrm{m}^{2} \mathrm{~h}$, were obtained from the experiments where the cake drying was not performed at all (in other words, the cake moistures are high). This is of course due to the considerably shorter cycle time. The capacities from the tests with steam drying and coagulant addition are, however, almost as good. This is due to the more open cake structure, which results in a faster filtration rate during the feeding, shorter pressing times and lower resistance to steam flow during the drying stage.

Although coagulants were not used for GCC, the capacities (Fig. 4B) were approximately double compared to those obtained for kaolin. The cake moisture contents could be significantly reduced by steam drying. In the best case, after steam drying at 9 bar, the residual moisture content was less than $3 \mathrm{wt} . \%$. As with the kaolin tests, high drying pressure was the main contributor to the low cake moisture contents.

One important outcome that was followed during the tests was the cake release from the filter cloth. Cake discharge was easy, especially in the experiments where steam was used for drying. The addition of coagulant did not seem to influence the cake release. The properties of the cloth also appeared to remain unchanged throughout the whole test series.

As presented in Fig. 5, steam drying for the dewatering of GCC is superior to air drying in terms of cake moisture. It is also clear that not only is the duration of the drying stage important, but that the application of high pressure helps to reduce the residual moisture content more effectively. It is possible that water cannot be pushed away from the smallest pores in the filter cake at 3 and 6 bar. Another explanation is perhaps the reduced ability of the steam to be condensed in the filter cake at elevated temperatures.

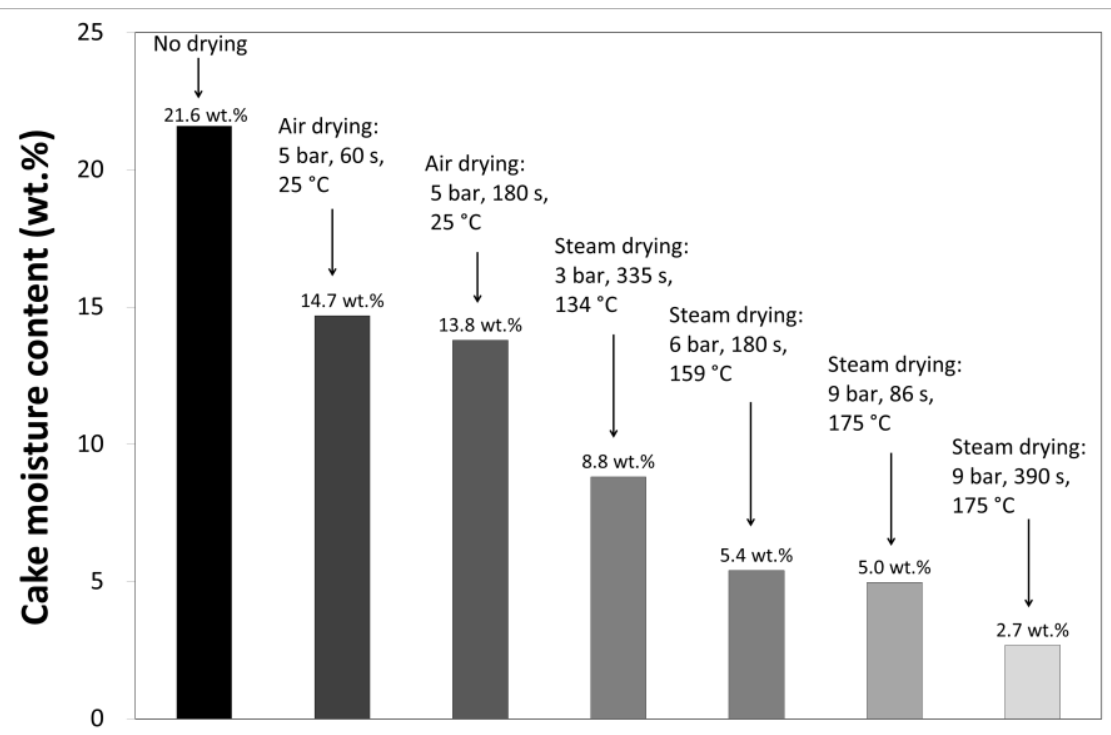

Fig. 5. An illustration of the decrease of the cake moisture contents obtained by air drying and steam drying of GCC filter cakes at various conditions. 


\section{Energy balance of steam drying}

The energy efficiency of the steam drying process for kaolin filter cakes was estimated based on the energy balance illustrated in Fig. 6. It was simply assumed that the energy content in the saturated steam fed into the filter was equal to the energy accumulated in the moist filter cake, heat energy loss and the outcoming heat energy in the filtrate. The energy accumulated in the filter cake was estimated by the sum of the energy requirements for heating the solids and the residual liquid. Most of the loss may have occurred as a result of thermal conduction out of the non-insulated filter chamber.

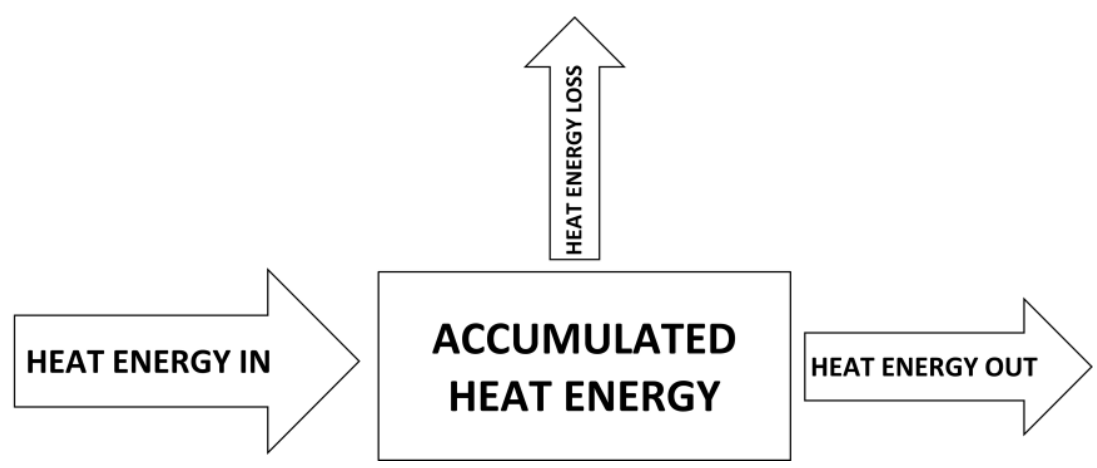

Fig. 6. Schematic diagram of the energy balance of the steam drying process.

The energy balance shown in Fig. 6 can be described by the equation:

$\Phi_{\text {in }}=\Phi_{\text {out }}+\Phi_{\text {loss }}+\Phi_{\text {acc }}$

The parameters in the energy balance can be estimated based on the data collected during the filtration and drying tests. The heat energy fed into the filter equals the heat energy content of the steam and it can be calculated from equation

$\Phi_{S}=m_{S} h_{S}(T, p)$

where $m_{S}$ is the mass of the steam fed into the filter and $h_{S}(T, p)$ is the specific enthalpy of steam at temperature $T$ and pressure $p$. The temperatures of saturated steam in the applied pressures of 6 , 8 , and 10 bar were $158,8^{\circ} \mathrm{C}, 170,4{ }^{\circ} \mathrm{C}$, and $179,9^{\circ} \mathrm{C}$, respectively. The corresponding specific enthalpies under these pressures were $2756 \mathrm{~kJ} / \mathrm{kg}, 2768 \mathrm{~kJ} / \mathrm{kg}$, and $2776 \mathrm{~kJ} / \mathrm{kg}$.

Because of the lack of a flow meter for steam, the steam consumption $m_{S}$ had to be estimated from the mass data collected. The basic assumption was that the mass of steam fed into the filter equals the mass of filtrate collected during the steam drying stage minus the mass of filtrate originating from the filter cake:

$m_{S}=m_{F}-m_{W C}$ 
where $m_{F}$ is the mass of filtrate collected during the drying stage and $m_{W C}$ is the mass of filtrate originating from the filter cake.

Masses of the filtrates were recorded by the data collection software, but the filtrate masses originating from the cake were estimated according to the results obtained from the reference tests. Two reference tests were carried out without any kind of cake drying, which means that the pores of these cakes were completely filled with liquid, i.e. the saturation of the cakes was $100 \%$. The moisture contents of the cakes were $29,6 \mathrm{w}-\%$ and $31,6 \mathrm{w}-\%$ and the average of these values was $30,6 \%$. This average moisture content was used in the calculations to describe the initial moisture content of all filter cakes before the drying stage. The mass of filtrate originating from the cake during the steam drying stage was estimated according to Eq.(8):

$m_{W C}=\frac{m_{\text {dry cake }}}{(1-0.306)}-m_{\text {wet cake }}$

where $m_{\text {dry cake }}$ is the mass of oven-dried cake and $m_{\text {wet cake }}$ is the mass of the cake after the steam drying stage.

The filtrate contains a quantity of heat that can be obtained from

$$
\Phi_{F}=m_{F} h_{F}(T, p)
$$

where $\Phi_{F}$ is the energy content of the filtrate collected during the drying stage and $h_{F}(T, p)$ is the specific entalphy of the filtrate at temperature $T$ and pressure $p$.

During the steam drying stage, filtrate was heated by (condensing) steam from the initial temperature of $21{ }^{\circ} \mathrm{C}$ to the final temperature of $99{ }^{\circ} \mathrm{C}$ at which point the drying was stopped. Although the filtrate temperature did not rise linearly during the steam drying stages (Fig. 3), an average value of $61{ }^{\circ} \mathrm{C}$ was used in the calculations for estimating the energy content of the filtrate collected. The specific enthalpy of water at $61{ }^{\circ} \mathrm{C}$ is $255.7 \mathrm{~kJ} / \mathrm{kg}$.

The energy accumulated in the filter chamber equals the energy needed to heat up the cake:

$$
\Phi_{\text {acc }}=m_{F, \text { cake }} c_{F} \Delta T+m_{\text {dry cake }} c_{K} \Delta T
$$

where $m_{F, \text { cake }}$ is the mass of filtrate in the cake after the steam drying stage, $c_{F}$ is the specific heat capacity of the filtrate $\left(c_{\text {water }}=4.19 \mathrm{~kJ} \mathrm{~kg}^{-1}{ }^{\circ} \mathrm{C}^{-1}\right), \Delta T$ is the temperature difference $\left(99{ }^{\circ} \mathrm{C}-23^{\circ} \mathrm{C}\right.$ $=76{ }^{\circ} \mathrm{C}$ ), and $c_{K}$ is the specific heat capacity of kaolin [19], $0.88 \mathrm{~kJ} \mathrm{~kg}^{-1}{ }^{\circ} \mathrm{C}^{-1}$.

The loss of heat energy caused by conduction out of the filter chamber and pipelines can be estimated according to the energy balance (Eq. 5) as follows:

$$
\Phi_{\text {loss }}=\Phi_{\text {in }}-\Phi_{\text {out }}-\Phi_{\text {acc }}
$$


The energy efficiency $\eta$ of the drying process can also be calculated from the energy balance presented in Fig. 6. In this case it is calculated from the equation:

$\eta=\frac{\Phi_{o u t}+\Phi_{a c c}}{\Phi_{i n}}$

The energy efficiencies of the drying process are presented in Fig. 7, which shows that drying can be generally performed with higher efficiency when the coagulant is used. Coagulation of the feed slurry also helps to reduce the variance between the energy efficiencies obtained in different conditions.

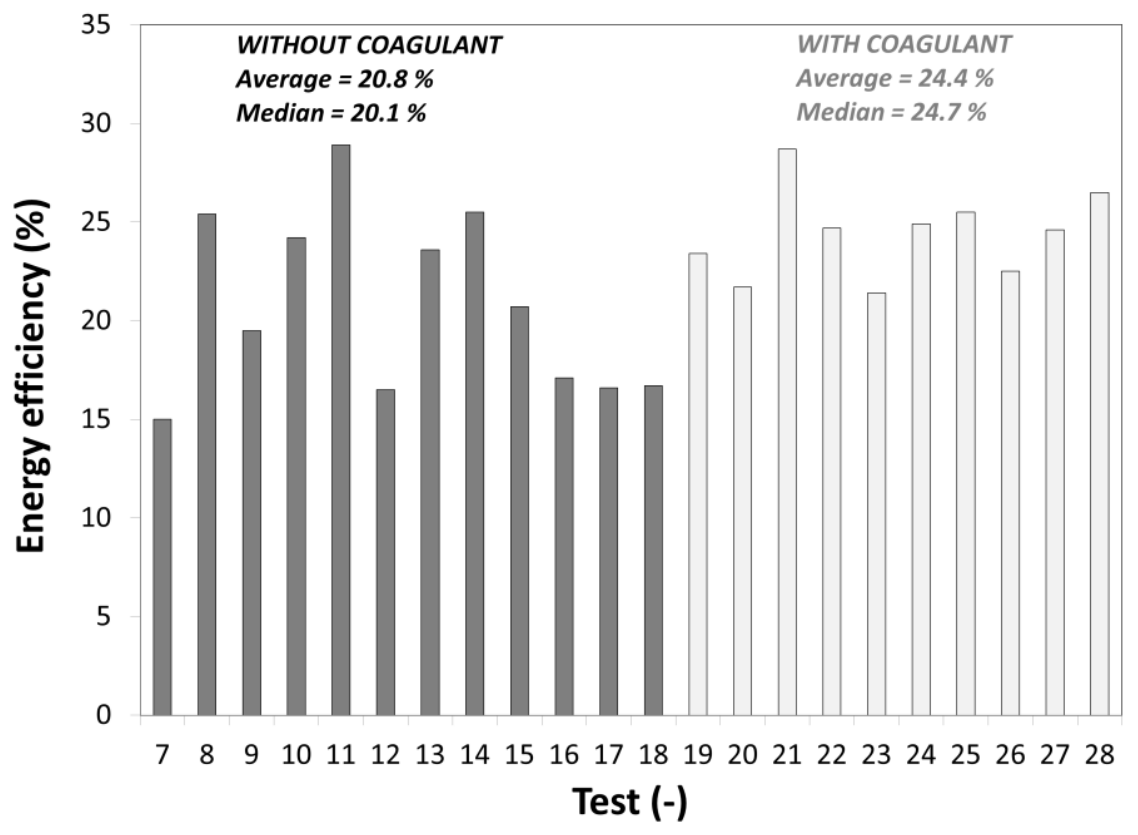

Fig. 7. Energy efficiencies (Eq. 12) for all steam drying experiments of kaolin.

According to the results presented in Fig. 7, only a relatively small proportion of the energy fed into the filter can be utilized for the cake drying. This indicated a large energy loss that most probably occurred by conduction through the chamber walls that were made of stainless steel. The outer temperature of the equipment increased significantly during the tests. Thus it is apparent that the material of the filter chamber plays an important role in the insulation of the filter.

One important explanation for the poor energy efficiency is the high cake resistance, which causes the condensation front to move very slowly through the cake. For this reason, a significant quantity of heat is consumed in heating up the equipment, whereas a smaller amount of energy is utilized for heating up the cake. In this case it is apparent that heat transfer by conduction inside the cake is very slow. This can be seen from Fig. 3, showing the temperature of the filtrate during the drying stage. The presented data shows that the most rapid increase in the filtrate temperature is obtained 
at the end of the drying stage before the filtrate temperature reaches $99{ }^{\circ} \mathrm{C}$ (before steam starts to flow from the filtrate pipe). These results suggest that the temperature difference between the upper and lower parts of the cake was significant (before the breakthrough point) and that the movement of the condensation front through the cake could be more accurately determined using several wellinsulated temperature sensors.

The conclusions presented above are also supported by the results of the energy balance calculations. The energy efficiency was slightly higher when the coagulant was used. As a result of coagulation, the cake resistances were lower and the structure of the cakes was more open. The average energy efficiency without the coagulant was $20.8 \%$, while the average efficiency with the coagulant was $24.4 \%$.

The energy consumption required for steam drying of each of the filter cakes, calculated from Eq.(2) and Eq.(10), are presented in Fig. 8. It can be observed that the results differ, or in other words, most of them lie above the diagonal. There are a couple of possible explanations for the differences: 1) the saturation of cakes in Eq.(2) was assumed to be 1, although it is likely to be smaller, 2) the estimated porosity and solid contents may be slightly inaccurate, 3) the measured cake thickness is not perfectly accurate because of irregularities in the cake shape, and 4) the cake thickness may change during the steam drying stage. Especially in the case of coagulant-aided filtration, the degrees of saturation may have been significantly below 1, since air was entrained into the thick slurry during mixing and pumping prior to filtration.

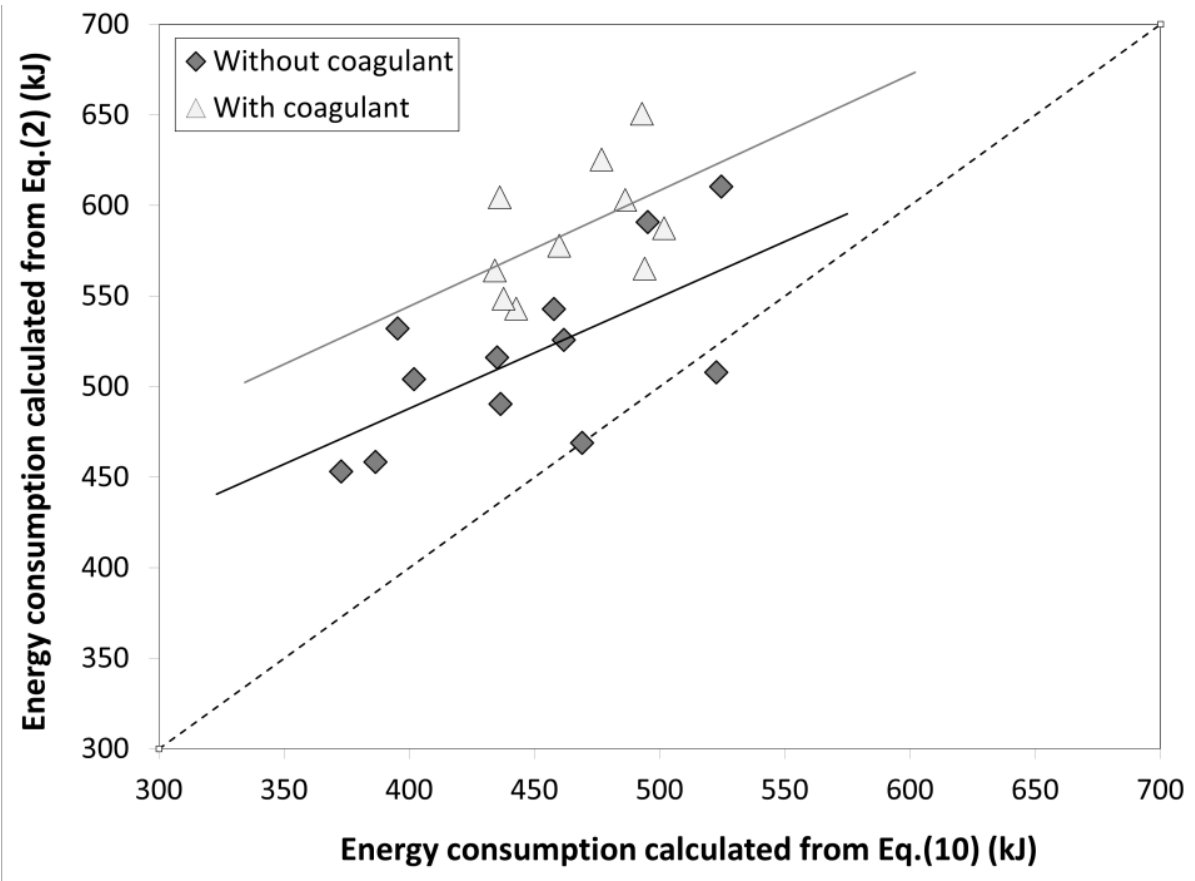

Fig. 8. Comparison of energy consumptions for steam drying of kaolin cakes calculated from two different equations. The energy consumptions with and without coagulant addition are also compared. 


\section{Comparison of steam drying with ideal thermal drying at atmospheric pressure}

The energy consumption of the steam drying process was also compared with an ideal thermal dryer $(\eta=100 \%)$ that evaporates water out of the filter cake. The energy balance of an ideal dryer was made for each test in such a way that the residual moisture content of the kaolin cakes would be equal to that of the steam-dried cakes. The first step in the thermal drying process is to heat up the entire cake from $23{ }^{\circ} \mathrm{C}$ to the boiling point of water. The energy required for this can be obtained from equation:

$\Phi_{D 1}=m_{F W, \text { cake }} c_{F} \Delta T+m_{\text {dry cake }} c_{K} \Delta T$

where $m_{F W \text {,cake }}$ is the mass of filtrate in the cake before the steam drying.

In the second step, water is evaporated from the filter cake until the residual moisture content is equal to that after the steam drying stage. The energy required for this step can be approximated:

$\Phi_{D 2}=Q_{h}\left(m_{F W, \text { cake }}-m_{F, \text { cake }}\right)$

where $Q_{h}$ is the heat of evaporation for water at 1.013 bar, $100{ }^{\circ} \mathrm{C} . Q_{h}=2257 \mathrm{~kJ} / \mathrm{kg}$.

Comparison between the theoretically calculated energy consumptions of an ideal thermal drier and the energy consumptions calculated from the data of the steam drying experiments is presented in Fig. 9.

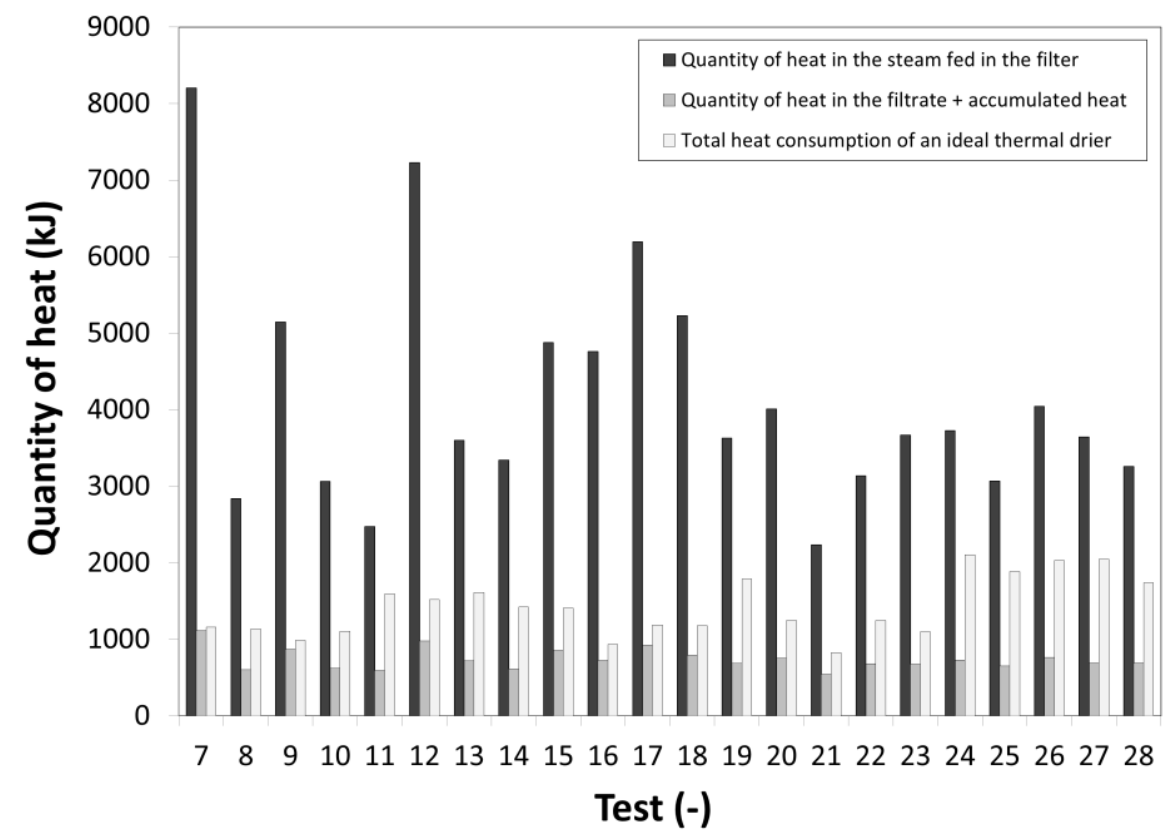

Fig. 9. Comparison between the estimated energy consumption of an ideal thermal drier and the energy consumptions calculated from the experimental data of the steam drying of kaolin in a pressure filter. 
The comparison presented in Fig. 9 shows that the energy consumption in an ideal thermal drier is larger than the energy needed to heat up the cake and the filtrate during the steam drying process. This can be explained by the fact that the stage requiring the largest amount of energy, i.e. evaporation of water from the cake, is largely eliminated in the steam drying process. In other words, the mechanical displacement effect is mainly responsible for the moisture removal from the filter cake. However, the energy of steam fed into the filter is much larger than the energy needed for the thermal drying. Therefore, the great loss of heat from the filter during the steam drying stage should be reduced by proper insulation. Additionally, it must be noted that in non-ideal thermal drying, some loss of heat also takes place. Quantification of that loss would, however, require reliable data from different kinds of thermal dryers.

One of the main advantages of steam drying performed in a filter unit is that the need for cake transport from the filter to a thermal dryer is eliminated. The combination of two unit operations in one device can also be expected to reduce the capital cost and to enable efficient heat recovery.

\section{Conclusions}

The target of this study was to determine the potential of the steam dewatering technique for two mineral suspensions, kaolin and GCC, using a pressure filter for both filtration and drying of the produced filter cakes. In both of these cases, exceptionally low cake moisture levels were obtained. The secondary objective was to compare the filterability of the original kaolin slurry with the slurry treated with a coagulant. With respect to the cake dryness, the use of coagulant resulted in a slight improvement, while its positive effect on the filtration capacity was more significant. The steam dewatering rates obtained for GCC were significantly higher, compared to kaolin.

It was found that it was possible to obtain a cake moisture level of less than $14 \mathrm{w}-\%$ for kaolin when the coagulant was used and the cake was pressed at 16 bar followed by steam drying at 10 bar pressure. In the case of GCC, extremely low cake moisture contents, even less than 3 wt.\%, could be achieved by $390 \mathrm{~s}$ of steam drying at 9 bar. The use of coagulant for the kaolin slurry helped to decrease the cake moisture contents when the steam drying pressure was 8 or 10 bar. However, in the steam drying experiments performed at 6 bar, such effect was not significant. For kaolin, the minimum time for the steam to penetrate through the cake was less than 3 minutes and the maximum was almost 30 minutes. The corresponding range for GCC was 1 to 8 minutes. Drying and pressing times were found to be shorter when the coagulant was used. The most important issue concerning future studies will be a more accurate estimation of the energy consumption. It has been showed in this paper that the potential of steam dewatering for difficultto-filter materials is very good but a comprehensive study still needs to be carried out comparing different types of traditional dryers with the steam drying technique.

\section{References}

[1] Peuker, U.A.; Stahl, W. Scale-up of steam pressure filter. Chemical Engineering and Processing 1999, 38, 611-619. 
[2] Peuker, U.A.; Stahl, W. Dewatering and washing flue gas gypsum with steam. Filtration \& Separation 2000, 37 (8), 28-30.

[3] Peuker, U.A.; Stahl, W. Steam pressure filtration: mechanical-thermal dewatering process. Drying Technology 2001, 19 (5), 807-848.

[4] Peuker, U.A.; Stahl, W. Scale-up and operation of a steam pressure filter in pilot scale. Chemical Engineering \& Technology 2001, 24 (6), 612-616.

[5] Gerl, S.; Stahl, W. Improved dewatering of coal by steam pressure filtration. International Journal of Coal Preparation and Utilization 1996, 17 (1\&2), 137-146.

[6] Bongers, G.D.; Jackson, W.R.; Woskoboenko, F. Pressurised steam drying of Australian lowrank coals Part 2. Shrinkage and physical properties of steam dried coals with very high porosity. Fuel Processing Technology 2000, 64, 13-23.

[7] Chen, Z.; Wu, W.; Agarwal, P.K. Steam-drying of coal. Part 1. Modeling the behavior of a single particle. Fuel 2000, 79, 961-973.

[8] Couturier, S.; Valat, M.; Vaxelaire, J.; Puiggali, J.R. Enhanced expression of filter cakes using a local thermal supply. Separation and Purification Technology 2007, 57, 321-328.

[9] Mahmoud, A.; Fernandez, A.; Chituchi, T.-M.; Arlabosse, P. Thermally assisted mechanical dewatering (TAMD) of suspensions of fine particles: Analysis of the influence of the operating conditions using the response surface methodology. Chemosphere 2008, 72, 1765-1773.

[10] Chantoiseau, E.; Arlabosse, P. Liquid pressure measurements in a thermally assisted mechanical dewatering process. Chemical Engineering Research \& Design 2010, 88 (8), 10781087.

[11] Bott, R.; Langeloh, T. Extremely low moisture contents by steam pressure filtration: the HiBar $^{\circledR}$ filtration is coming up. XX International Mineral Processing Congress (IMPC), Aachen, Germany, September 21-26, 1997.

[12] Wimmerstedt, R. Steam drying - history and future. Drying Technology 1995, 13 (5-7), 1059-1076.

[13] Douglas, W.J.M. Drying paper in superheated steam. Drying Technology 1994, 12 (6), $1341-1355$.

[14] Pang, S.; Pearson, H. Experimental investigation and practical application of superheated steam drying technology for softwood timber. Drying Technology 2004, 22 (9), 2079-2094. 
[15] Jensen, A.S. Industrial experience in pressurized steam drying of beet pulp, sewage sludge and wood chips. Drying Technology 1995, 13 (5-7), 1377-1393.

[16] Uengkimbuan, N.; Soponronnarit, S.; Prachayawarakorn, S.; Nathkaranakule, A. A comparative study of pork drying using superheated steam and hot air. Drying Technology 2006, 24 (12), 1665-1672.

[17] Speckhahn, A.; Srzednicki, G.; Kumar, D. Drying of beef in superheated steam. Drying Technology 2010, 28 (9), 1072-1082.

[18] Pronyk, C.; Cenkowski, S.; Muir, W.E. Drying foodstuffs with superheated steam. Drying Technology 2004, 22 (5), 899-916.

[19] Xanthos, M (Ed.). Functional fillers for plastics. $2^{\text {nd }}$ ed. WILEY-VCH Verlag Gmbh \& Co. KGaA, Weinheim, 2010. 